\title{
Communication/Comunicação
}

\section{Parasitological stool sample exam by spontaneous sedimentation method using conical tubes: effectiveness, practice, and biosafety}

\author{
Exame parasitológico de fezes pelo método de sedimentação espontânea utilizando tubos \\ cônicos: eficácia, praticidade e biossegurança
}

Steveen Rios Ribeiro ${ }^{1}$ and Cinthia Furst ${ }^{2}$

\begin{abstract}
Introduction: Spontaneous sedimentation is an important procedure for stool examination. A modification of this technique using conical tubes was performed and evaluated. Methods: Fifty fecal samples were processed in sedimentation glass and in polypropylene conical tubes. Another 50 samples were used for quantitative evaluation of protozoan cysts. Results: Although no significant differences occurred in the frequency of protozoa and helminths detected, significant differences in protozoan cyst counts did occur. Conclusions: The use of tube predicts a shorter path in the sedimentation of the sample, increases concentration of parasites for microscopy analysis, minimizes the risks of contamination, reduces the odor, and optimizes the workspace.
\end{abstract}

Keywords: Spontaneous sedimentation. HPJ method. Intestinal parasites.

\section{RESUMO}

Introdução: A sedimentação espontânea é um procedimento importante para o exame parasitológico de fezes. Uma modificação desta técnica utilizando tubos cônicos foi realizada e avaliada. Métodos: Cinquenta amostras de fezes foram processadas em cálices de sedimentação de vidro e em tubos cônicos de polipropileno. Outras 50 amostras foram usadas para avaliação quantitativa de cistos de protozoários. Resultados: Embora não tenham sido encontradas diferenças significativas na frequência de helmintos e protozoários identificados, houve diferença significativa na contagem de cistos de protozoários. Conclusões: $\mathrm{O}$ uso do tubo prevê um caminho mais curto na sedimentação da amostra, aumenta a concentração de parasitas para a análise microscópica, minimiza os riscos de contaminação, reduz o odor e otimiza o espaço de trabalho.

Palavras-chaves: Sedimentação espontânea. Método HPJ. Parasitas intestinais.

Intestinal parasite diseases are still considered a public health problem, especially in developing countries where sanitation conditions are inadequate ${ }^{1}$. Diagnosis of these parasites is based on microscopic analysis of fecal samples aimed at detecting the evolutionary forms, whether as eggs, larvae, cysts, oocysts, or trophozoites; a successful outcome becomes more likely when using a technique based on the principle of concentrating these stages. Numerous laboratories use the sedimentation method Hoffman, Pons and Janer (HPJ), because it is easy to perform, has low cost,

1. Programa Pós-graduação em Doenças Infecciosas, Núcleo de Doenças Infecciosas, Universidade Federal de Espírito Santo, Vitória, ES. 2. Departamento de Patologia, Universidade Federal do Espírito Santo, Vitória, ES.

Address to: Dra Cinthia Furst Leroy Gomes Bueloni. Av. Marechal Campos 1468, Maruípe, 29040-091 Vitória, ES, Brasil.

Phone/Fax: $55272122-7295$

e-mail: cinthiafurst@hotmail.com

Received in 02/12/2010

Accepted in 01/02/2011 and shows good sensitivity for diagnosing both helminths and protozoa using fresh or preserved feces ${ }^{2}$. Since the description of the use of sedimentation to diagnose parasites, reported by Lutz in $1919^{3}$, several modifications of the technique have been proposed to facilitate its implementation and increase its efficiency.

In this communication, our group proposes the use of 50-ml conical polypropylene tubes instead of traditional sedimentation glass to perform the HPJ method and evaluates the degree of agreement between the sedimentation methods.

Fifty stool samples were used from the parasitology sector of the Department of Pathology of the Federal University of Espírito Santo. Feces were homogenized in the collection container, using a disposable spatula. After homogenization, they were separated into two aliquots of $10 \mathrm{~g}$ : One aliquot was prepared by the HPJ method in sedimentation glass consisted of inverted cone of $200 \mathrm{ml}$ capacity mounted on a base like a goblet, and the other was prepared for sedimentation in a 50- $\mathrm{ml}$ conical bottom polypropylene tube (Falcon ${ }^{\circledR}$-type tube). In both techniques, filtered water was used as homogenization solution, and the supernatant was discarded after 1 hour of sedimentation. The sedimentation process was repeated twice to clarify the sediment. For each sediment sample, three slides (coverslip of $24 \times 32 \mathrm{~mm}$ ) were examined under light microscopy on the same day by the same examiner using lugol for staining.

For quantitative evaluation of protozoan cysts, another 50 stool samples known to be positive for protozoa were used. Sedimentation of these samples was performed as described in the preceding paragraph. The supernatant of the final sedimentation was discarded, and a $1-\mathrm{ml}$ aliquot of sediment was transferred to a tube in which $4 \mathrm{ml}$ of $0.15 \mathrm{M}$ sodium chloride $(\mathrm{NaCl})$ were added. Following homogenization, cyst counts were performed in a Neubauer Chamber, in duplicate.

Data analysis was performed using the Chi-square test to compare the frequency of parasites diagnosed with both methods and by the paired Student's t-test to compare the results of the quantitative evaluation of protozoan cysts. Kappa statistics (k) were used to determine the strength of agreement between methods. The SPSS program, version 11.5 for Windows, was used, and p values less than 0.05 were considered statistically significant.

The procedures were performed in accordance with the ethical standards of the National Health Council. The study was approved by the Ethics Research Committee of the Center for Health Sciences at the Federal University of Espírito Santo under protocol number 004/07. 
Of the 50 fecal samples examined, 16 were positive for helminths by the HPJ method and 18 using the Falcon ${ }^{\circledR}$-type tube. Regarding protozoans, 15 were positive by HPJ and 16 by the Falcon"-type tube. Almost perfect agreement was achieved in the diagnoses of helminths $(\kappa=0.82)$ and protozoa $(\kappa=0.95)$ (Table 1$)$.

No statistically significant differences in the data were verified when the individual frequencies of species of nematodes and protozoa were compared between methods using the Chi-square test (Table 2).

Quantitative analysis of protozoan cysts showed a tendency to recover a greater number of cysts for the conical tube. Statistically significant differences were verified when using the paired Student's t-test (Table 3).

Analysis of the results revealed that spontaneous sedimentation using the conical tube was consistent with that observed in the HPJ method (Table 1). When a nonsignificant disagreement occurred between the two methods, in the majority of cases, it was favorable to the use of the Falcon ${ }^{\circledR}$-type tube in relation to traditional sedimentation (Table 2). One example was Enterobius vermicularis, identified in three cases using the conical tube method, but no cases were identified using the traditional HPJ method. Considering that eggs of E. vermicularis can occur in reduced numbers in fecal samples, often presenting false negative results in the HPJ method, the conical
TABLE 1 - Occurrence of helminths and protozoa detected by the sedimentation techniques in sedimentation glass (HPJ) and in a 50-ml conical bottom polypropylene tube (Tube) in $\mathbf{5 0}$ stool samples and the value of agreement (Kappa) between the two techniques.

\begin{tabular}{|c|c|c|c|c|}
\hline & \multicolumn{2}{|c|}{$\begin{array}{c}\text { Helminths } \\
\mathbf{k}=0.82^{*}\end{array}$} & \multicolumn{2}{|c|}{$\begin{array}{r}\text { Protozoa } \\
\mathbf{k}=0.95^{*}\end{array}$} \\
\hline & HPJ + & HPJ - & HPJ + & HPJ- \\
\hline Tube+ & 15 & 3 & 15 & 1 \\
\hline Tube- & 1 & 31 & 0 & 34 \\
\hline
\end{tabular}

${ }^{*}$ Kappa value indicates almost perfect agreement. HPJ: Hoffman, Pons and Janer.

tube showed the potential of increasing the chances of detecting the eggs due to improved sedimentation, aided by internal vertical walls, in contrast to the angled walls of the sedimentation glass.

Although no statistically significant differences occurred between the traditional HPJ method and conical tube sedimentation regarding the frequency of helminths and protozoa diagnosed, use of the conical tube presented some important advantages. The $50-\mathrm{ml}$ conical tubes on the market have screw caps, so sedimentation of feces can be protected to avoid contamination between laboratory samples or by external agents, such as ants and flies. It was also possible to reduce the smell, which could contribute to minimizing the attraction of insects in areas of diagnosis, an important condition for quality control.

TABLE 2 - Comparison of the occurrence of helminths and protozoa observed in the parasitological exam of 50 stool samples, using sedimentation glass (HPJ) and a 50-ml conical bottom polypropylene tube (Tube).

\begin{tabular}{|c|c|c|c|c|}
\hline & \multicolumn{2}{|c|}{ HPJ } & \multicolumn{2}{|c|}{ Tube } \\
\hline & $\mathbf{n}$ & $\%$ & $\mathbf{n}$ & $\%$ \\
\hline \multicolumn{5}{|l|}{ Helminths* } \\
\hline Ascaris lumbricoides & 7 & 14.0 & 7 & 14.0 \\
\hline Hookworm & 8 & 16.0 & 8 & 16.0 \\
\hline Trichuris trichiura & 5 & 10.0 & 4 & 8.0 \\
\hline Strongyloides stercoralis & 3 & 6.0 & 4 & 8.0 \\
\hline Schistosoma mansoni & 1 & 2.0 & 2 & 4.0 \\
\hline Enterobius vermicularis & 0 & 0.0 & 3 & 6.0 \\
\hline \multicolumn{5}{|l|}{ Protozoa** $^{* *}$} \\
\hline Giardia lamblia & 7 & 14.0 & 7 & 14.0 \\
\hline Entamoeba coli & 9 & 18.0 & 9 & 18.0 \\
\hline Entamoeba histolytica/Entamoeba dispar & 4 & 8.0 & 4 & 8.0 \\
\hline Endolimax nana & 5 & 10.0 & 6 & 12.0 \\
\hline Iodamoeba butschlii & 0 & 0.0 & 1 & 2.0 \\
\hline
\end{tabular}

${ }^{*} \chi^{2}: 3.30$, p: $0.653{ }^{* *} \chi^{2}: 1.02$, p: 0.907; HPJ: Hoffman, Pons and Janer.

TABLE 3 - Mean number of cysts per ml of sediment, quantified in a Neubauer Chamber, after sedimentation in conventional sedimentation glass (HPJ) and conical bottom polypropylene tube (Tube) of 50 stool samples positive for protozoa.

\begin{tabular}{|c|c|c|c|c|}
\hline Protozoa & $\mathbf{N}$ & $\begin{array}{c}\text { Mean } \pm \text { SEM } \\
\text { HPJ }\end{array}$ & $\begin{array}{c}\text { Mean } \pm \text { SEM } \\
\text { Tube }\end{array}$ & $\begin{array}{c}\text { p } \\
\text { value* }\end{array}$ \\
\hline Entamoeba coli & 16 & $17578.1 \pm 6707.6$ & $24609.3 \pm 6390.8$ & 0.040 \\
\hline Endolimax nana & 17 & $86029.4 \pm 33663.8$ & $106250.0 \pm 42497.8$ & 0.296 \\
\hline Giardia lamblia & 10 & $40000.0 \pm 14942.0$ & $77500.0 \pm 25141.9$ & 0.034 \\
\hline Isospora belli & 5 & $1250.0 \pm 1250.0$ & $3750.0 \pm 1530.9$ & 0.374 \\
\hline Entamoeba histolytica/Entamoeba dispar & 2 & $0.0 \pm 0.0$ & $3125.0 \pm 3125.0$ & 0.500 \\
\hline Total & 50 & $43000.0 \pm 12673.0$ & $60000.0 \pm 16159.4$ & 0.022 \\
\hline
\end{tabular}

SEM: standard error of the mean, HPJ: Hoffman, Pons and Janer; N: number of stool samples. * paired Student's t-test. 
The space used to perform the method was smaller, as conical tubes can be maintained in compact supports, reducing the risk of accidents and improving safety during the laboratory routine.

Observation of the slides under an optical microscope verified that the proposed change presented better results in relation to the number of protozoan cysts visualized, a result that was confirmed by the quantitative evaluation (Student's t-test).

In conclusion, the use of conical polypropylene tubes for spontaneous sedimentation presented practical advantages over the use of sedimentation glass, especially in relation to safety in the laboratory, the elimination of odors, and the smaller area used; it also permitted greater concentration of protozoan cysts.

\section{ACKNOWLEDGMENTS}

The authors would like to thank the staff of the Laboratory of Parasitology, particularly Mr. Fausto Edmundo Lima Pereira and Mrs. Adriana Oliveira Costa, and the Federal University of Espírito Santo.

\section{CONFLICT OF INTEREST}

The authors declare that there is no conflict of interest.

\section{REFERENCES}

1. Frei F, Juncansen C, Ribeiro-Paes JT. Epidemiological survey of intestinal parasite infections: analytical bias due to prophylactic treatment. Cad Saude Publica 2008; 24:2919-2925.

2. Hoffman WA, Pons JA, Janer JL. The sedimentation-concentration method in Schistosomiasis mansoni. Puerto Rico J Publ Hlth 1934; 9:281-298.

3. Lutz A. O Schistosomum mansoni e a Schistosomatose segundo observações, feitas no Brazil. Mem Inst Oswaldo Cruz 1919; 11: 121-150. 